\title{
THE CONSERVATION OF MADAGASCAR'S ORCHIDS . A MODEL FOR AN INTEGRATED CONSERVATION PROJECT
}

\author{
PhILLIP CRIBB $^{1,2} \&$ JOHAN HERMANS ${ }^{1}$ \\ 'Royal Botanic Gardens, Kew, Richmond, Surrey TW9 3AE, UK. \\ ${ }^{2}$ Author for correspondence: p.cribb@rbgkew.org.uk
}

\section{Introduction}

The fauna and flora of the large island of Madagascar, situated in the eastern Indian Ocean off the coast of East Africa, has been recognised for many years as one of the most peculiar anywhere in the world, and as one of the most endangered. It has a rich orchid flora of about 1000 species. Over $90 \%$ of its orchid species are endemic to the island and nearly $20 \%$ of its genera. Endemicity of its orchids at both the species and generic level is higher that anywhere else in the world. Many orchids are threatened by the rapid rate of environmental change in the island.

The joint Royal Botanic Gardens Kew / Parc Tzimbazaza Threatened Plants Programme, supported by the Ministry of Natural Resources and Forestry and by the University in Antananarivo, has adopted an innovative and integrated approach to plant conservation, using orchids, palms and succulents as its target groups. The starting point for the programme has been the production a new and detailed vegetation map of the island which pin-points all the vegetation types, including those that are not currently protected. This has been adopted by the government to earmark new reserves and protected areas. Orchid distributions, past and present, can be located on the map in order to see if species currently enjoy a degree of protection within reserved areas.

Six flagship orchid species have been used to raise local awareness of the threats to native orchids through an out-reach and poster programme in schools. Extensive field studies have established the distribution, numbers and genetic diversity of the target species. Seedlings have been raised in situ for eventual re-introduction and to provide nurseries with legitimate sources of rare species. The ecology of areas selected for re-introduction has been assessed.
Planned re-introduction will only be undertaken when the appropriate monitoring programmes have been established.

Orchids are found in almost every environment in the island, and many species are threatened with extinction because of the rapid and extensive destruction of natural habitats by agriculture, mining and fire. A Field Guide to the orchids of the island is in preparation which should enable the orchids to be identified and named in the wild, an aid to the utilisation of orchids as a means of rapid assessment of the plant diversity and environmental health of habitats. This will be particularly useful since most modern surveys, relying on zoological rather than overall biological diversity, may well provide an inaccurate assessment of the value of a habitat for conservation purposes.

\section{Madagascar}

The Indian Ocean island of Madagascar lies about $400 \mathrm{~km}$ from the east coast of Africa, the tropic of Capricorn running through the south and the northern tip pointing towards the equator. At $587,000 \mathrm{~km}^{2}$ it is the fourth largest island in the world and larger than California and Oregon combined. It is thought that the first inhabitants arrived from Indonesia and Malaya between 1500 and 2000 years ago followed by migration from mainland Africa and elsewhere. Today it has a population of about 16 million people and almost as many zebu cattle, it is not a rich country. Traditional exports include minerals, prawns, vanilla and lychees but major investments are being made in new industries. Tourism, especially ecotourism, is growing but still a relatively small money earner for the country.

The island has a great variety of bedrock and soil types as well as wide topographical variation, ranging 
from tropical coastal forest to several mountain ranges over $2000 \mathrm{~m}$. It separated from the mainland about 165 million years ago as a result of continental drift and, in this way, a largely endemic flora and fauna developed, there being an exceptional level of endemism. An estimated 9500 different vascular plants, $81 \%$ of them endemic, are found there; at the last count 980 different orchids in 59 genera have been recorded, suggesting that over one in ten vascular plants on Madagascar are orchids. The endemic flora and fauna has fascinated explorers for centuries but our knowledge of it is still surprisingly limited.

\section{Vegetation zones}

The island has been divided into a number of fairly well defined areas of vegetation and climate, but more recently detailed mapping techniques, such as satellite imaging, have been used to re-define some of these zones. Innovative work by Du Puy \& Moat (2003) and Moat (2005; www.vegmad.org), for example, matched underlying geology with vegetation. In addition, detailed analysis of the natural history of Madagascar has been published by a large group of authors in Goodman \& Benstead (2003), giving further insight in the island's natural diversity. The following is a summary of the distinct areas of vegetation on Madagascar, it will also illustrate the delicate ecology of some representative orchids.

\section{The eastern rain forest}

This vegetation zone, covers a large part of the island and occurs from the north down the east to the southeast corner of the island. It runs from the coast to the crest of mountains lying parallel to the eastern length of the Island. This part of the country is under the influence of the South-east trade winds, which promote cloud formation and heavy rainfall throughout the year. Average annual rainfall is over $2000 \mathrm{~mm}$, topping $6000 \mathrm{~mm}$ in parts of the Masoala peninsula in the north-east. There is no marked dry season at lower elevations and only a brief one higher up where it is cooler so that broad-leaf evergreen forest is supported. Temperatures are generally high with mean winter readings in the coolest season ranging from $18^{\circ} \mathrm{C}$ at sea level to $10^{\circ} \mathrm{C}$ at the top of the escarpment. Primary vegetation is mostly lowland rain forest with tall forest trees (up to $25-30 \mathrm{~m}$ ) but there are several distinct strata in the forest and a diffuse understory. This type of forest is rich in species. It is in much better condition in the north and north-east than further south where just a patchwork remains. This type of vegetation continues in the north-west around the Sambirano river valley where there is a short dry season and about $1800 \mathrm{~mm}$ of rainfall. In cultivation plants of this area will need to be kept fairly moist throughout most of the year, the amount of heat and light required will vary much from species to species. Cymbidiella flabellata, for example, grows as a terrestrial in boggy areas and is sometimes seen in great quantity, plants can be fully exposed to sunlight near the sea but it can also be found at the edge of forest or beneath ericaceous scrub (Philippia). On the other hand Cymbidiella falcigera almost invariably grows on Raphia palms in marshy ground, the root system of the orchid is very elaborate and runs deeply into the soft bract fibre of the palm. This species is very difficult to establish in cultivation. The third species of this endemic genus is C. pardalina which lives in association with Platycerium madagascariense, a staghorn fern with net-veined sterile fronds. This association seems essential, at least in nature, for the development of the orchid. The roots of the orchid develop in the crown of sterile fronds of the fern that form a protective shell against direct sunlight and desiccation. Ants also often establish themselves in the crown of fronds of the fern. The orchid and fern live epiphytically up to $20 \mathrm{~m}$ high on tree trunks, most commonly Albizia, this whole combination forming a very complex and vulnerable micro-ecosystem.

The eastern forest is the home of numerous orchids, the following are just a selection of the more unusual ones. Beclardia macrostachya often grows in semishade, while from the same habitat comes Oeonia rosea with its colourful lip. Angraecum rubellum is a twig epiphyte, the flowers are only a few millimetres but the pink colouration makes it very unusual. Microcoelia gilpinae is another colourful angraecoid; it is leafless and grows in the deep shade entwined amongst twigs. Bulbophyllum is well-represented as a genus with about 200 different species; one gem growing in deep shade and embedded in moss is Bulbophyllum analamazoatra. Bulbophyllum hamelinii is the giant of the genus with leaves almost $40 \mathrm{~cm}$ long and a large, 
malodorous inflorescence. Polystachyas can be found in the lower strata of the forest and also on the ground; there are over 20 different species on the island. It is often difficult to identify them because the flowers may look superficially similar but are variable in colour and size. Polystachya clareae with its bright orange flowers is readily identified. A fair number of Liparis species can be found in leaf litter on the forest floor, a distinctive one being Liparis longicaulis with a long rectangular stem and flowers that can be up to $3 \mathrm{~cm}$. Gastrorchis are amongst the most colourful terrestrial orchids in the area: Gastrorchis tuberculosa being one of the most striking; G. pulchra var. perrieri seems to thrive in cultivation (G. steinhardtiana is a synonym of it).

One of the highlights of the Madagascar orchid flora is Cynorkis, of which there are about 120 different species, most of them terrestrial but several species can be found growing in moss as true epiphytes like the tiny $C$. peyrotii. Others grow lithophytically, one of the finest examples being $C$. lowiana with very large flowers, which grows on dripping rocks in deep shade. Physoceras is very close to Cynorkis, the main difference is that the leaf is carried on a long stem. Physoceras violaceum grows in thick moss at the base of trees or on lower branches.

\section{Central highlands and mountains}

Although there is some overlap with the eastern habitats, the central plateau, including a number of mountain ranges, covers nearly $40 \%$ of the island. The climate is more seasonal than the east, with an annual rainfall between 1200 and $2500 \mathrm{~mm}$, and there are frequent mists in some areas. Mean temperature in the coldest months ranges from over $13^{\circ} \mathrm{C}$ in the East and West down to $5^{\circ} \mathrm{C}$ in high mountain zones. The remaining forest is very much fragmented and mainly composed of moist montane forest. The tree canopy is up to $25 \mathrm{~m}$ with low-branched trees bearing numerous epiphytes, and there is a thick herbaceous understory. At higher elevations or on exposed ridges there are formations of sclerophyllous montane vegetation, also known as lichen forest, with smaller trees, again many epiphytes, but the understory is quite open and the soil is covered with moss and lichen. At lower altitude the principal vegetation consists of ericoid thicket, with a dwarf open habit generally just a few metres in height. These areas of open woodland are sometimes dominated by Tapia, Uapaca bojeri. The trees have thick, fire-resistant bark allowing them to survive the fires which almost annually burn the coarse grassland around them. Tapia belongs in the family Euphorbiaceae, the fruit being edible. The tree is a host of the Malagasy silkworm, from which beautiful textiles are woven.

There is a very different ecosystem towards the summit of the mountains. Frosts and blizzards have been reported during the early morning hours of the dry season, a period lasting approximately seven to eight months, but mist and dew are common. These areas are recognised as containing many endemic plants with highly restricted distribution. Many of the massifs are not protected, although they contain numerous locally endemic species. The region is spotted with inselbergs (isolated monoliths of smooth rounded granite) in the central area and these have similar characteristics. Most of the region, however, consists of a complex blend of hills and valleys, covered by vast expanses of depauperate grassland or pseudosteppe of a few cosmopolitan fire-adapted grasses. There is evidence that some of this grassland was once thinly wooded. Apart from vast tracts of introduced trees like Pine and Eucalyptus, these are also the main areas of human habitation and food production. The region rests on degraded laterite soils. Annual man-induced fires are used to produce new herbaceous growth for grazing. In localities protected from fire some forest survives, particularly in gulleys. The orchids of these areas are now becoming quite scarce, most relying on specific microhabitats to thrive. They include many of the species that are seen in cultivation in Europe and elsewhere; it is the region closest to the capital Antananarivo and so it has been more heavily collected. Typical orchids from the region are: Angraecum magdalenae, growing in small groups on rocky outcrops, often sheltered by boulders or rock faces. The plants have slightly succulent leaves, large, fleshy flowers emerge on a short stem from beneath the leaf. Angraecum sorori$u m$, also from mountainous ground and tapia forest can grow quite tall, up to one metre, with elongated thin leaves. Smaller angraecums found in lichen forest or near the summit of some of the mountains are Angraecum popowii and A. rutenbergianum, both 
bearing relatively large flowers. From moister and more shaded forest comes the monotypic Lemurorchis madagascariensis.

In many ways the terrestrial orchids of this area are even more exciting and interesting. Cynorkis are very well represented with some large and colourful species: C. gibbosa can occasionally be seen on the roadside and is not uncommon in the foothills of some of the mountain ranges. The leaves have characteristic darker patches and can be $60 \mathrm{~cm}$ long, they develop over a very short period, the plant flowers and the leaves then die back. Another locally common species found near cultivated land is Eulophia plantaginea, growing along streams and even reported in drainage ditches around rice paddies. Two of the most colourful terrestrials are the blue Disa buchenaviana which grows in fairly dry grassland and is locally common and $D$. incarnata grows in the same area but is always seen in boggy ground, it often grows together with Satyrium trinerve.

\section{Dry areas of the south $\&$ west}

The land gradually slopes westwards from the Central Highlands to the coast with remaining forest extending in a broad zone towards the coast from the northern tip of the island. The western zone receives rainfall only during the wet season with a dramatic reduction from the north to the south, ending in areas that receive less than $400 \mathrm{~mm}$ of precipitation per year. The area supports a variety of sclerophyllous deciduous woodland, open woodland and wooded savannah plus small patches of humid vegetation along rivers and in Raphia marshes. The main primary vegetation consists of western deciduous forest which is hot and dry. Rainfall averages $500-1500 \mathrm{~mm}$ and there is a long dry season of 5 to 10 months, having a profound effect on the vegetation.

The deciduous forest changes towards the south into spiny forest. Here the canopy is 10 to $15 \mathrm{~m}$ tall. The extreme south and south-west have an average rainfall of $700 \mathrm{~mm}$ or less, the driest parts not even getting $300 \mathrm{~mm}$. The climate is arid and hot, the average annual maximum temperature is 30 to $33^{\circ} \mathrm{C}$, the minimum $15-21^{\circ} \mathrm{C}$. Many plants have adaptations to store what little moisture is available and to minimise water loss. Vegetation is mainly low growing. This xerophytic forest, also known as spiny forest or bush, is dominated by Euphorbia and Didieraceae, the world's greatest diversity of baobabs and many other endemic succulents occur here. It is interspersed with limestone formations with their own unique vegetation. The northern part of the island is characterised by a wide variety of topography, with high mountain peaks and coastal plains. Its climate is similar to that of the east except for a much drier pocket at the northern tip.

Orchids in these habitats are not plentiful but they make up for this by their variety of form and interesting adaptation to extreme conditions. A species like Grammangis spectabilis from the Zombitsi forest in the south-west is a smaller and modified form of $G$. ellisii which is widespread on the eastern side of the island. Paralophia epiphytica has an interesting history; fragments of evidence of the existence of this unusual epiphyte go back to the 1970s. The horticulturalist Marcel Lecoufle found two epiphytes with Eulophia-like flowers growing on palm trees in the vicinity of Tõlanaro. One was identified as Eulophia palmicola, which had been described by the Henri Perrier de la Bâthie in 1935. The other was left with Jean Bosser at the Muséum in Paris who recognised it as a possible new species, but unfortunately insufficient herbarium material was available and he decided to await further evidence. In 1994 we found large colonies of the beautifully scented epiphyte in full flower in cultivated oil palms next to a swampy area of Raphia palms near Fort Dauphin, early the next year a group of botanists from the Royal Botanic Gardens, Kew visited the same site, herbarium and a living collections were made and the latter flowered at Kew in May 2001. With good herbarium material available Cribb et. al. then described it as Eulophia epiphytica. Based on molecular study it was recently placed in its own genus and is now known as Paralophia epiphytica (Cribb \& Hermans, 2005). The host trees and the orchid have now almost completely disappeared; only few very small colonies remain.

The genus Sobennikoffia is restricted to warm and dry areas. Little difference can be found between the two main species: S. robusta has different leaves and a longer spur than $S$. humbertiana. The ultimate in succulence comes in the leafless Vanilla. Vanilla perrieri, with its impressive bright yellow flowers, is commonest in coastal scrubland, or littoral forest. 
The dry soil of this area provides the habitat for a variety of interesting terrestrials. The genus Oeceoclades is mainly found here and shows a fascinating array of shape and colour of plant: species like Oeceoclades spathulifera, O. gracillima (now incorporating $O$. roseovariegata) and $O$. boinensis have not just interesting flowers but also very intricately patterned leaves.

\section{Orchid Mapping}

We are involved in an interesting project at the Royal Botanic Gardens Kew to reassess the vegetation of Madagascar. Up-to-date maps of surviving primary and secondary vegetation have been compiled using satellite imagery and ground-truthing. The resulting maps have provided the Madagascan Government with a template for the erection of new reserves to ensure that all the distinctive habitats of the island are protected. Previously, less than 50\% were covered in Nature Reserves and other protected sites, mainly because the data on which they were based came from zoological sources. In particular, some distinct vegetation types, such as those found on high mountains, tapia forests, inselbergs and other specialised areas have been greatly reduced in extent and were not included in any of the current national parks or protected areas.

We have also been able to assess the distribution and vulnerability of some Madagascan orchid species. Distribution maps have been constructed, mainly based on data from herbarium sheets and other vouchered specimens with the data collected from the larger European and Madagascan herbaria and including historic as well as more recent records. The distribution patterns are being plotted onto maps that distinguish the remaining vegetation on the island based upon details of aerial mapping, geology and elevation (Du Puy \& Moat in press). These maps can be used to indicate where species occurred historically, whether the vegetation they once occupied still persists and where a species might be found in surviving stands of natural vegetation. The maps confirm that some species are indeed endangered but also that others survive in several localities although often in very restricted habitats.

Some species have a limited geographical range, like Eulophiella elisabethae which is only found on the Masoala peninsula in the north-east. The orchid favours the palm Dypsis fibrosa as a host.

Eulophiella roempleriana is restricted to a narrow ecological range, only being found in the crown of tall screw-pines, Pandanus, which in turn grow in swampy ground in forests. Its distribution is confined to the eastern forest from Ranomafana in the southeast to Isle aux Nattes in the north-east, where the few remaining plants are used as a tourist attraction. In contrast, Angraecum longicalcar, A. magdalenae and $A$. henrici are more restricted in their distribution, being found on the central plateau in confined habitats. The results (Cribb et al., in press) also suggest that species from the eastern rain forest are currently in decline and that those from the central plateau probably declined many years ago when the central plateau was cleared. Angraecum sesquipedale is widely distributed throughout the eastern part of the island but it is most common near the coast. Towards the south there are small scattered populations in littoral forest. Here they grow terrestrially in white sand that is now being mined for titanium dioxide. Some of the populations, but by no means all, from the dry south have narrower leaves and a single-flowered inflorescence, this variant was described as $A$. sesquipedale var. angustifolium but is still seen in cultivation under its old name of $A$. bosseri.

Another interesting observation was made regarding Aerangis ellisii, which rather puzzlingly was recently put on Appendix 1 of CITES, together with, for some reason, two of its synonyms. We all know that the species is fairly common in cultivation from seed-grown stock and there is no shortage of plants in nurseries. When looking at its distribution it is clear that the species is widespread, growing epiphytically in the eastern forest and rock on higher ground. In many ways it has a relatively good chance to escape extinction or even endangerment.

\section{Threatened Plant Appeal}

Kew, along with its partner institutions, is committed to an integrated approach to plant conservation that combines in situ and ex situ methods. In other words, it is useless protecting species if their habitats are disappearing. We need to conserve the habitats so that, if plants become threatened, remedial action can be taken such as better management of the environ- 
ment or even reintroduction of endangered species.

Notwithstanding the commitment by the new Madagascar government to its natural resources, there is little doubt that much of the island's unique flora and fauna are under threat. The main encroachment comes from agriculture and fires running out of control from grass burning to stimulate new grass growth. These fires are almost essential for the survival of the large herds of cattle which are so important to Malagasy culture. Other threats are from logging, gathering for fuel, mining and to some extent collecting of desirable species, a few orchids are also harvested for medicinal purposes like Vanilla madagascariensis and some Eulophia \& Cynorkis species. There is surprisingly little information available on the conservation status of the orchids on the island, as a consequence there has been little systematic conservation planning. Several major projects, notably by the Royal Botanic Gardens Kew in collaboration with Parc Tzimbazaza and other local and international partners, are trying to address this.

One of the major initiatives is the Madagascar Threatened Plant appeal organised through the Friends of Kew which has not only raised a considerable amount of money but also created a greater awareness of the challenges Madagascar faces. The aim is to produce an integrated approach to plant conservation, utilising a number of horticulturally interesting orchids, palms and succulents as flagship species. The six target orchids are: Aeranthes henrici, Angraecum longicalcar, A. magdalenae, Bulbophyllum hamelinii, Eulophiella roempleriana and Grammangis spectabilis. Funds have been spent on conservation assessments and research on distribution. The Centre Technique Horticole d'Antananarivo has been able to purchase materials and equipment for micro-propagation of the target species, a new orchid house at the Parc Tzimbazaza near Antananarivo has been constructed and others renovated for ex-situ conservation. Training has been provided and extensive fieldwork by Kew and local botanists has been undertaken. Work has concentrated on assessing conservation status, distribution and the study of population structure and pollination biology. A long-term aim is to reintroduce selected species to areas from which they have been lost. Efforts by private individuals and nurseries have also contributed to the wider availability of seed-grown orchids. Surplus seedlings will be sold through the trade to finance further work. Educational material in the form of posters and displays have been produced in three languages: Malagasy, French and English.

\section{Orchids as environmental indicators}

A checklist and bibliography of the orchids of Madagascar was published more than 5 years ago (Du Puy et al., 1999), the book has now sold out. The work sparked a renewed interest in the orchids of Madagascar and surrounding islands; important fieldwork was undertaken by several individuals and organisations. This, together with the continued work by the botanists working at the Herbier National in Paris, especially Jean Bosser, has meant that a considerable amount of additional information has become available. Several genera have been revised and new species described.

Madagascan Orchids, a revised version of the Checklist and Bibliography (Hermans et al. 2007), will be published shortly and this will be another step towards a full revision of the orchid flora of the region. In the new book, the checklist has been updated, idiosyncrasies in nomenclature have been resolved, much additional information on distribution, habitat and flowering time has been extracted from herbarium collections and incorporated and a number of oversights and errors have been amended. Almost one hundred changes in nomenclature are proposed in the new book A large number of species are illustrated. Further details can be obtained from j.harris@rbgkew.org.uk.

Orchids are found in almost every habitat in Madagascar and are ideal plants for use as indicators of environmental health. We have a good idea of where orchids were historically distributed, field work is providing a clear idea of modern distributions and threats. An illustrated Field Guide to Madagascan Orchids is in an advanced state of preparation that will allow plants to be named in the field. Distributions affected by environmental changes can then be rapidly monitored. The orchid data can then be assessed alongside data from birds, butterflies, lemurs, amphibians and reptiles to provide a clearer idea of the health and conservation needs of any particular habitat. 
ACKNOWLEDGEMENTS. We would like to thank Jean Bosser, Clare Hermans, David Roberts and David Du Puy for continued advice and encouragement.

\section{LITERATURE CITED}

Cribb, P., D. Roberts \& J. Hermans. 2005. Distribution, ecology and threat to selected Madagascan Orchids. In: Selbyana. Proceedings IOCC II. In press.

Du Puy, D., P. Cribb, J. Bosser, J. \& C. Hermans. 1999. The orchids of Madagascar, annotated checklist and annotated bibliography. Royal Botanic Gardens, Kew. $424 \mathrm{p}$.
Du Puy D. \& J. Moat. 2003. Using geological substrate to identify and map primary vegetation types in Madagascar. Pp. 51-67 in: S. Goodman \& J. Benstead. 2003. The Natural History of Madagascar. University of Chicago Press, Chicago \& London.

Goodman, S. \& J. Benstead. 2003. The Natural History of Madagascar, University of Chicago Press, Chicago \& London. 1709 p.

Hermans J. \& C., P. Cribb, J. Bosser \& D. Du Puy.2007. Madagascan Orchids. Royal Botanic Gardens, Kew.

Moat, J. 2005. Vegetation map of Madagascar. At www.vegmad.org.

Dr Phillip Cribb studied at Cambridge and Birmingham in England before, in 1974, joining the staff of the Royal Botanic Gardens, Kew, where he was Deputy Keeper of the Herbarium and Curator of the Orchid Herbarium until his retirement in March 2006. He currently holds Honorary Fellowships at Kew and at the Royal Holloway College, University of London. He has participated in many expeditions to study plants in the field, especially in the tropics of Africa, Madagascar, SE Asia, the Americas and the Pacific. He is the author or co-author of over 360 scientific papers and books on orchids. His current research is concentrated on a new classification and evolution of the family Orchidaceae, and on the taxonomy and conservation of orchids. He was Chair of IUCN (The World Conservation Union)/Species Survival Commission’s Orchid Specialist Group from 1994 until 2005.

Johan Hermans has travelled extensively in Madagascar. He is, by profession a conservator and is currently head of the conservation department at the Museum of London. He is the author of many articles on orchids and co-author of Orchids of Madagascar (1999) and Angraecoid Orchids (2006). He is currently an Honorary Research Associate at the Royal Botanic Gardens, Kew, chairman of the Royal Horticultural Society's Orchid Committee and of it Advisory Panel on Orchid Registration. He is also a keen orchid grower and has specialised in Madagascan orchids. 